\title{
The Design of English Test Software Based on .NET Framework
}

\author{
LI Zhaoying ${ }^{1, \text { a }}$ \\ ${ }^{1}$ Jilin Business and Technology College, Changchun 130507, China \\ alizhaoying@yeah.net
}

Keywords: English Test Software; .NET Framework; ASP.NET

\begin{abstract}
With the rapid development of computer network technology and Chinese education informatization level unceasing enhancement, various applications based on Internet more and more be favored by the people. Online examination system is along with the network technology and database technology and developed gradually. Online examination system is an extension of the traditional examination room, infinite vast space, it can take advantage of the network anytime and anywhere to test students, coupled with the use of database technology, which greatly simplifies the process of traditional examination. This paper introduces the network online exam system of related theory and technology background, aimed at the feature of online examination system, using the. NET technology, design the system database table structure and relationships and finally realizes a three-tier architecture based on B/S structure, with ASP.NET technology as support to English test software system.
\end{abstract}

\section{Introduction}

Network technology gradually penetrates into all aspects of social life today, the traditional examination way are also facing changes, and network examination is a very important direction. Network test software based on Web technology can be done with the aid of the Internet around the world, so the test can be either locally, it can also be carried out in another place, greatly expand the flexibility of the exam. Papers can be generated according to the contents of the question bank instantly, can avoid before the exam; And it can use a large number of standardized tests, using the computer to re-mark, greatly improve the efficiency of reading; It also can send results to the database directly, statistics, sorting, and so on. So now it is a good test method for network examination, examination questions content on the server, the candidate by name, admission ticket number and password to $\log$ in, the exam answer is stored in the server, so that the fairness of the exam, the answer of security can be effectively guaranteed [1-2]. Therefore, the use of network examination way will be the trend of the development of the test in the future.

\section{Overview of the software system related technology}

As a developing language, ASP.NET is a dynamic WEB application technology, it is based on _NET frame, abandoned VB script and Java script language, and use based on .NET framework SDK supported by VB.NET the modularized program design language [3]. This makes the rapid development of powerful Web applications and services can be implemented. ASP.NET technology provides a convenient, flexible approach to building, deploying, and running WEB applications, as well as for any browser or the equipment. ASP.NET application to run for the first time need to be compiled, compile after don't modify the source code do not need to recompile, so in terms of speed and efficiency can be much higher than that of ASP technology. At the same time it also has the reusability of code, maintainability, and many other advantages. Compared with other Web technologies, ASP.NET can more quickly and more easily establish a flexible, secure and stable Web applications. ASP.NET is the next generation of ASP products, but not the ASP simple upgrade. It is the ASP had the very big enhancement in performance, not only make it easier for developers to create dynamic Web content, can also make it easier to create complex and stable Web application [4]. The work process is shown in figure 1. 


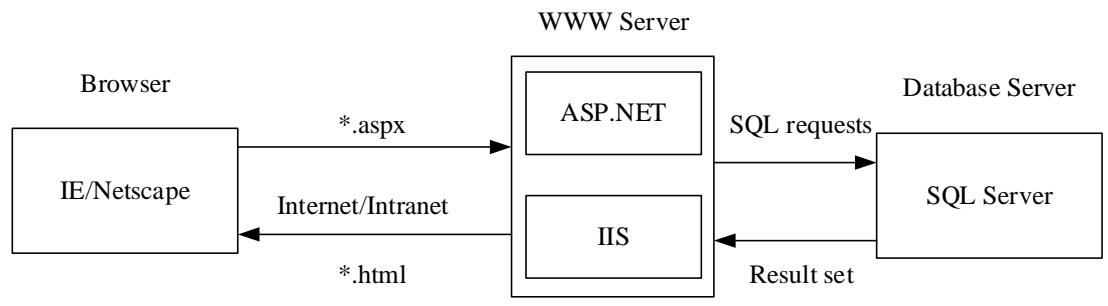

Figure 1. The spatial data processing based on Web

With the rapid development of network technology, an increasing number of network information, database access technology is more and more attention by all of us, the ADO.NET data access technology has been widely support and praise. In the past, most Web pages are static letter rev, composition, Web sites only allow visitors to read data, Web site interactivity is not strong, and do not store the information of the visitor, if you must store the information of visitors, you need to use the database and data access strategy, allowing the data access strategy - allows programmers and database connection is established, and to provide search, insert, update, and delete data command. ADO.NET effectively from data manipulation, data access is decomposed into multiple can be used alone. ADO.NET for SQL Server, OLEDB and XML data source access, user applications can use ADO.NET very easily connected to the data source, retrieve, and update the data operation [5]. ADO.NET component structure are shown in figure 2 below.

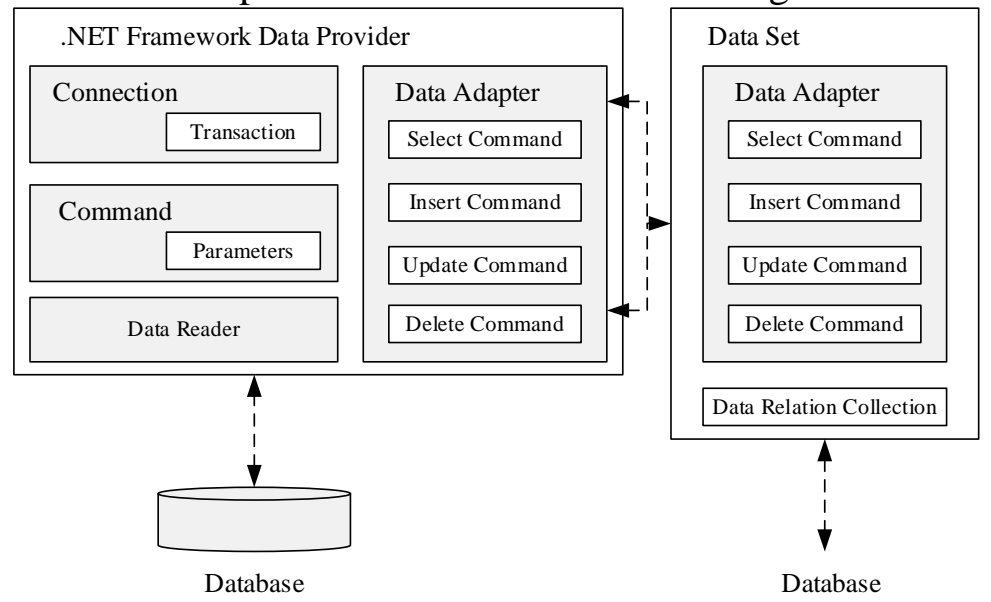

Figure 2. System structure of ADO.Net

\section{Requirements analysis for English test software system based on the.net framework}

The system goal is to provide professional English test electronic platform, can let the examinee all through the computer professional English course in all kinds of examination, the examinee after submit the examination paper can generate the examinee information and automatic marking the given test scores files. System main function is shown in figure 3.

The examination management subsystem. The subsystem is the application of database resources of maintenance, management platform, mainly includes the database resources of the query, add, modify, delete, etc.

The examination paper management subsystem. The subsystem is mainly to test paper of archive management, including content browsing/paper and papers and tests, archive, delete operation. Has been used by the paper can be archived in the examination paper archives, use for future inquiry.

The examination paper automatic system. This subsystem has realized the online examination system has the function of the automatic group volume, namely in the/topic, the difficulty of the title, chapter, teaching requirements as degree distribution of the multiple constraint conditions by using the genetic algorithm for automatic group volume. After test paper generation, teachers can be viewed on paper, and make appropriate adjustments. 
Online examination system. The online examination system has realized the student's online examination and self-test function. System by accepting students enter the right of personal identity information and enter the online examination system, and carries on the online answering question within the prescribed period of time, if more than the test time, the system will automatically submit test paper.

Reading score subsystem. Papers submitted after the subsystem, will automatically be submitted to the database, the answer to the question of automatic marking, and will result in the result table.

Statistical analysis subsystem. The subsystem can be carried out a statistical analysis to the result of the exam, including statistics student body of the highest and lowest points, each point of the total number, the average rating. To grasp the learning situation of students; It can also view the correct for each question, through the statistical analysis, to rewrite the test according to the measured values of related attribute index of the item.

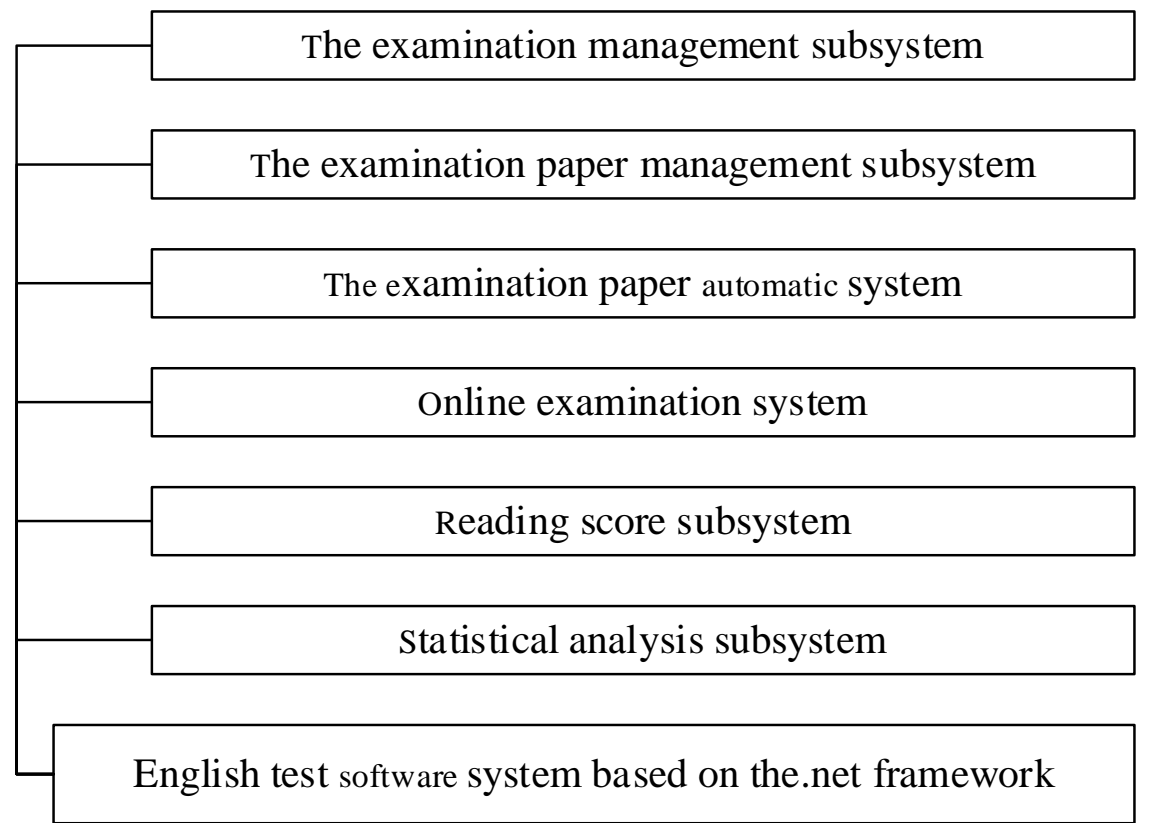

Figure 2. Function of English test software system based on the.net framework

\section{Architecture design of the system based on ASP.NET}

Because of the English test software for the construction of the purpose is to change the traditional test mode, achieve one-way communication from the is given priority to with the teacher to students as the main form of two-way communication, the role of the teachers from the previous leading to leading, interactive teaching to cultivate students' autonomous learning, cooperative learning group and exploratory learning ability. In developing integrated campus network and Internet access, therefore, the campus environment, information platform, the overall architecture of the proposed interactive B/S structure, which includes the user interface layer, application layer and the middle three layers of data management database and server structure, build the user as the core of structured information resources organization, as shown in figure 3.

The system mainly use Microsoft Visual Studio 6.0 as a development tool, using SQL Server2000 as the database storage system, using ASP.NET to develop application software. System design mainly includes the examination management, examination paper management, online examination, reading score subsystem and statistical analysis. Because of time, space, and considering the should keep pace with the construction of campus network and other reasons, the system only the implementation and test of some functional modules, unrealized parts need to be in the next step in the process of the use of further enrich and perfect. 


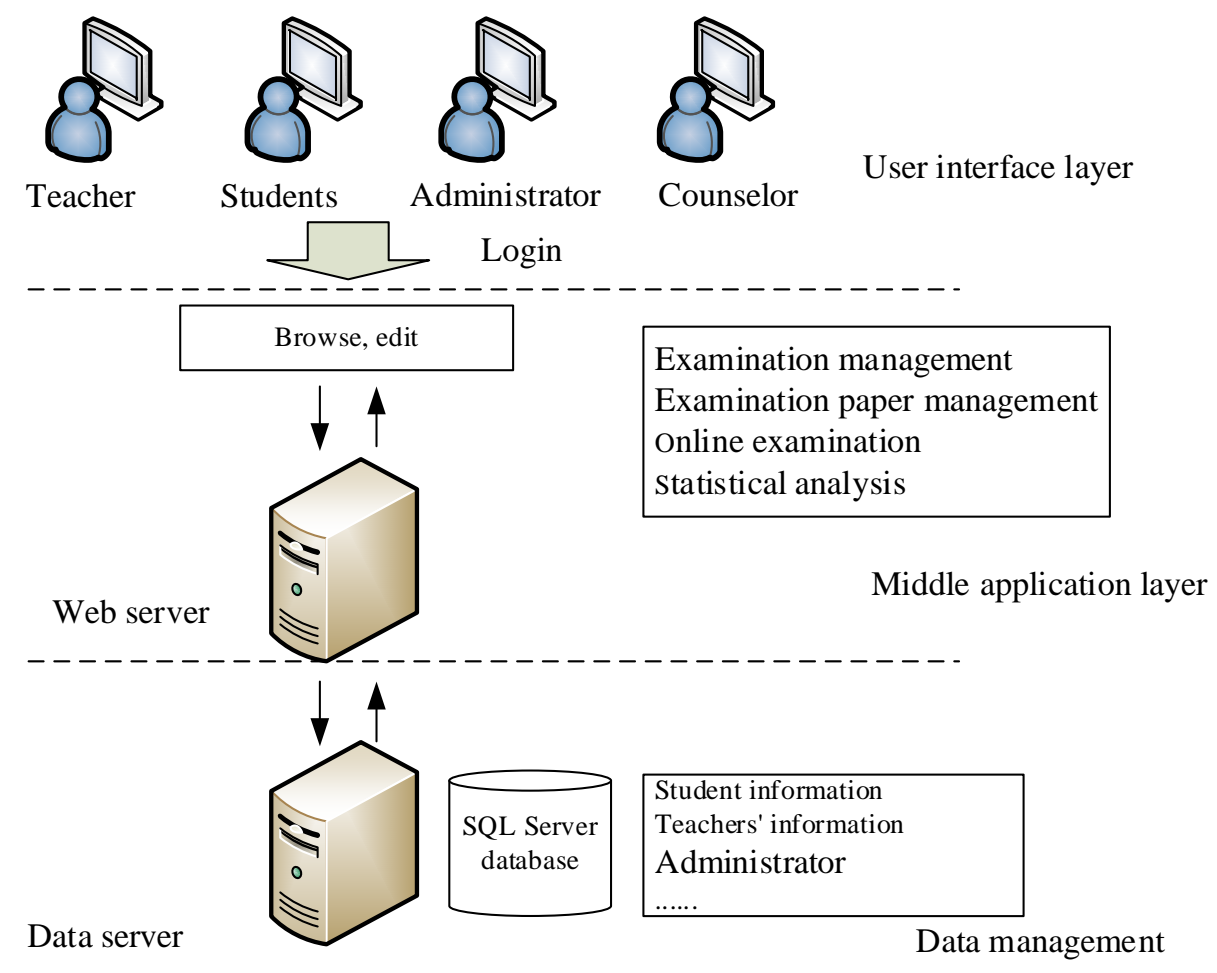

Figure 3. The architecture of the system based on ASP.NET

\section{Conclusion}

With the popularity of Internet, more and more schools in the form of online examination, the use of network for no floppy disk, paperless online exam, greatly improve the reliability of the examination, effectiveness, reduce the test cost. This paper describes the test way of history, status quo and the ASP.NET platform, and an overview of SQL Server2000 database management system. To scientific and effective use of information network resources and technical advantages, demand analysis was carried out on the online examination system, and to the whole process of online examination system structure analysis, mainly introduced the realization of online examination system process. Use the process of the software system is based on the examination paper setting, generate, student examination, examination results query to realize network exam, making English test can easily through the Internet and LAN.

\section{References}

[1] C.J. Cooper, S.P. Cooper, D.J. Del: Epidemiologic Perspectives \& Innovations, Vol. 3(2006) No.1, p. 1.

[2] Z.J. Fan: Computer Science, Vol. 4(2007) No.8, p. 80.

[3] S. HUANG, S. CHEN: Computer Technology and Development, Vol. 2(2010), p. 51.

[4] W. Min: Journal of Convergence Information Technology, Vol. 6(2011) No.1, p. 147.

[5] S.C.W. Kong, H. Li, T.P. Hung: Automation in construction, Vol. 13(2004) No.2, p. 261. 